\title{
LAS ANOTACIONES EN CARACTERES LATINOS DE LAS GUARDAS DEL MS. ALJAMIADO-MORISCO J. XIII
}

Por

TORIBIO FUENTE CORNEJO

Recientemente en el $4 .^{\circ}$ Congreso sobre Moriscos, mi colega et profesor A. Vespertino Rodríguez en un trabajo titulado «El discurso de la luz de Mohamed Rabadán y la literatura aljamiada de los últimos moriscos en España», ha demostrado que ya a finales del siglo XVI y priricipios del XVII, los moriscos españoles escribían sus textos en caracteres latinos, coexistiendo, naturalmente, con los escritos en caracteres árabes (1).

En efecto, la fuerte presión religiosa, cultural y lingüística, ejercida por la Inquisición en el siglo XVI, sobre todo en la segunda mitad, dio lugar a un hibridismo o, mejor, a una pérdida de identidad entre los moriscos, uno de cuyos máximos exponentes fue, sin duda, el olvido de la lengua árabe e incluso del alifato por la mayoría de los moriscos, para quienes el empleo de éste habia llegado a constituir, según las palabras de Hegyi, un signo externo de su pertenencia a la umma o comunidad islámica (2). Algunos autores moriscos, fuesen creadores propiamente dichos o fuesen traductores o simples amanuenses, bien por sus escasos conocimientos de la lengua árabe, bien por necesidades de proselitismo, se vieron en la obligación de escribir sus obras en caracteres latinos para poder, de esta forma, ser leídos y entendidos, incluso ya antes de su expulsión en el año 1609 (3).

De los documentos escritos en caracteres latinos quisiera llamar la atención so-

(1) Véase RODRiGuEZ, A.V.: «E/ discurso de la luz de Mohamed Rabadán y la literatura aljamiada de los últimos moriscos en España", págs. 9-11 del texto mecanografiado.

(2) Véase HEGYI, O.: Cinco leyendas y otros relatos moriscos, Madrid, Gredos, CLEAM 4, 1981, pág. 17.

(3) Para una compieta información sobre los mss. aljamiado-moriscos escritos en caracteres latinos cfr. RODRíGUEZ, A.V., op. cit., págs. 9-11 (del texto mecanografiado). En mi tesis doctoral, Poesía religiosa aljamiadomorisca, de próxima aparición, estudié el Romance Altísimo proctetor escrito en caracteres latinos antes de la expulsión. 
bre las anotaciones que aparecen en las guardas de algunos mss. aljamiado-moriscos (4), pues éstas nos proporcionan unos datos que, sin duda, nos ayudarán a conocer con más precisión el nivel de adaptación de los últimos moriscos españoles, así como a esclarecer, en la medida de lo posible, el problema de los escribanos moriscos.

En este trabajo me propongo editar y estudiar las guardas del manuscrito XIII de la Biblioteca de la Junta, en las cuales hay indicaciones de ese tipo. Distinguiré entre guardas iniciales y finales fundamentalmente por dos razones: una, porque son obra de amanuenses diferentes; y, otra, por la naturaleza del tema que tratan.

\section{Las guardas iniciales}

Son el resultado de la transliteración en caracteres latinos de un texto aljamiadomorisco. En el cual se explica un método para calcular hipotéticamente la aparición de la luna del mes de rajab, séptimo mes del calendario lunar árabe, durante un período aproximado de quince o dieciséis años, aunque, en cualquier caso, adaptando las fechas musulmanas a las del calendario cristiano (5). Y, además, se anota la comprobación real de dicho cálculo desde 1581 hasta 1587. Veamos lo que dice el texto:

fol. 1 Este (6) é el quento(to) (7) de la[s] (8) / lunas dende el año m/il i qinientos (9) y ojenta (10) y uno (11)/.

5 Parecyó la luna de ralğal (12) a dos de agosto i parecerá / en nel año de mil i qinientos y ojenta (13) $y$ dos a beinte i dos dle ulio dos dias más o menos sin / dudarl.

10 Pareció la luna lde rajğal eln el año de [mil i qinilento/s i ojenta (14) i dos a beinte i dos / de ulio, domingo en la tarde $\%$ Y tomamos rağal lunes a ben(t)/titrés de uliyo sin dudarll.

(4) Los mss. a.jamiado-moriscos con anotaciones en caracteres latinos en las guardas son los siguientes: J. 4, J. 13, J. 24, J. 29, J. 57, J. 66, J. 72, J. 80, J. 81, J. 82, J. 83, J. 84, J. 85, J. 93, J. 94, J. 95 y J. 98.

(5) Hay también en otros manuscritos indicaciones, igualmente en caracteres latinos, similares a las que voy a estudiar. Haré mención tan solo de las del manuscrito número 4 de la Junta, a las cuales me referiré más adelante.

(6) En el original casi todo este apartado está muy borroso.

(7) Utilizo el paréntesis para indicar las letras que aparecen en el original y que se deben suprimir.

(8) Cuando la lectura resulta imposible o cuando falta alguna palabra o incluso una letra, empleo los corchetes para indicar las reconstrucciones que se han hecho.

(9) Hay un rasgo sobre la vocal i que quizá indique el valor patatal de la n: siendo posible la lectura qiñientos.

(10) Son varias las grafías utilizadas por el amanuense para representar la antigua y moderna $\hat{C}$ romance. En la edición del texto transcribo todas las grafias de las guardas iniciales con el signo \%, y en nota doy la grafía correspondiente. En este caso o è enta.

(11) En el ms. J. 4 hay en las guardas indicaciones para el cómputo de las lunaciones de rajab a partir del año 1580.

(12) Para esta palabra siempre se emplea la grafía $\&$, la misma que para la prepalatai fricativa sonora, y para la oclusiva velar sonora romances. Para evitar confusiones transcribo la palabra rağal con ğ, la prepalatal con j y la oclusiva con $q$.

(13) En el ms. $\circ$ enta.

(14) En el ms. o $\mathcal{k}$ enta. 
fol. 2 [Parecerá la luna de r]ağalll [en el] año de mil i qinientos i ojenita (15) y tres a doze de ulio dos dias / mas o menos sin dudarl.

5 En el año de mil i qinientos [ochen]ta i tres / y en el [se prencipia el] (16) quen/to de Alfri]ca (17) a qynze i marco seze (y) / y qaldla año se sube onze dias/.

10 Pareciyó la luna de rağal en el año de / mil i qinientos i ojenta (18) i tres, a dizisiete / de ulio (19)\%.

Parecerá la luna de rağal en el año de / mil i qinientos i ojenta (20) i qu[a]tro, a oyo (21) de ullio, dos dias más o menos sin dudart.

15 Pareciyó la luna de rrağal en el año / de mil y qinientos i ojenta (22) i qualtro, a (23) nuebe de uliyo, dia de lunes/.

20 Parecerá la luna de rağel en el año / de mil i ginientos i ojenta (24) i cinqo, a benti/[nueve de julio, dos dias más o menos sin dudarll.

fol. 3 [Pareçió la luna de rağal en el año / de mil qinientos i oljenta (25) i cinqo (26), a bintfinj/ube de juliyol.

5 Parecerá la luna de rağal en el año de / mil i qinientos i ojenta (27) i seis, a dizinuelbe de juliyo, dos días más o menos sin du/dar. Ternéis quenta ermanos/.

10 Pareció la luna de rağal en ell año de mil i

(15) En el ms. o $\ell$ enta.

(16) En el ms. J. 4, que está estudiando YOLANDA PIEDRA FONSECA, hay una indicación que dice:

En el año de mil i quinientos i ojenta prencipial el quento de Africa de la luna, a catorze i marco qynze I i qada año se sube onze dias, y se aqaba en marco i prencipia.

A continuación el morisco da la fecha real a partir de la cual se inicia el cálculo:

Pareció la luna de rağal en el año de mil i qinientos / i lojjenta a treze de agosto, un día más o menos, i se sube / a qada año diez dias. De á adelante tendréis quenta...

(17) Esto es, «comienza el cómputo según el sistema árabe». Para la reconstrucción véase la nota anterior

(18) En el ms. o \& enta.

(19) Posiblemente sea más correcto leer julio.

(20) En el ms.o $\mathcal{E}$ enta.

(21) En el ms.o $\hat{\varepsilon}_{0}$

(22) En el ms. $\circ$ \& enta.

(23) En el ms. hay un signo sobre la o y la a: quatro a.

(24) En el ms. $\circ$ \& enta.

(25) En el ms. o $q$ enta.

(26) En el morisco escribió $z$ y luego sobrescribió $c$.

(27) En el ms. o \& enta. 
qinientos i ojenta (28)/ y seis, a diziojo (29) de juliyol.

15 Parecerá la luna de rağal / en el año de mil i qinientos it ojenta (30) i siete, a ojo (31) de julityo, un día más o menos. Ternéis qulenta (32).

Pareciyó la luna de rağal en el / año (33) de mil $i$ qinientos i / ojenta (34) i sielte, a siete de juliyo (35)\%.

20 Parecerá la luna de rağal en el / año (36) de mil i qinientos i ojenta (37) i oljo (38), a binteisiete de mayo, dos días / más o menos. Ternéis quentall.

\section{Las guardas finales (39)}

Son obra de Luis Escribano, quien anotó las fechas de los momentos más significativos en la vida de su familia, ocurridos entre 1572 y 1582 . A saber, la muerte de su abuelo, de su padre y de dos hermanos, su matrimonio con Jerónima la Navarra y el nacimiento de dos de sus hijos.

Hay asimismo tres anotaciones de época posterior, fol. 1, 1-6, escritas por otro amanuense del cual sólo sabemos que se apellidaba De Brea, en las cuales da noticia de las fechas del nacimiento de tres hijos suyos. He aquí el texto:

fol. 1

Item naçió Ysabel de Brea, fija mía, a XXII de dezilembre del anio 1593/.

5 Item nació Veatriz de Brea, fija mía, postrero día / de febrero anio 1598 (41)\%.

(28) En el ms. o ç enta.

(29) En el ms. dizio $₹ o$.

(30) En el ms. op eq enta.

(31) En el ms.o cqo.

(32) A continuación escribe quando de manera caligráfica, y en la linea siguiente y en caracteres árabes, sin vocalizar, Al/ah cinco veces.

(33) En el ms. ano.

(34) En el ms. 0 \& enta.

(35) Entre líneas y al final vuelve a escribir quando en caligrafia.

(36) Cfr. nota 7.

(37) En el ms. $\circ$ \& enta.

(38) En el ms.o $h o$.

(39) La letra y el sistema gráfico utilizado son distintos, por lo que se puede pensar en otro copista diferente.

(40) El mal de estado de conservación del ms. impide la lectura de estas dos líneas de escritura.

(41) Estas dos últimas anotaciones son obra de otro amanuense. Quiero expresar mi gratitud a Da. María Josefa Sanz Fuentes, Catedrática de Paleografía de la Universidad de Oviedo, sin cuya ayuda no hubiese sido posi. ble la lectura correcta de estas dos anotaciones. 


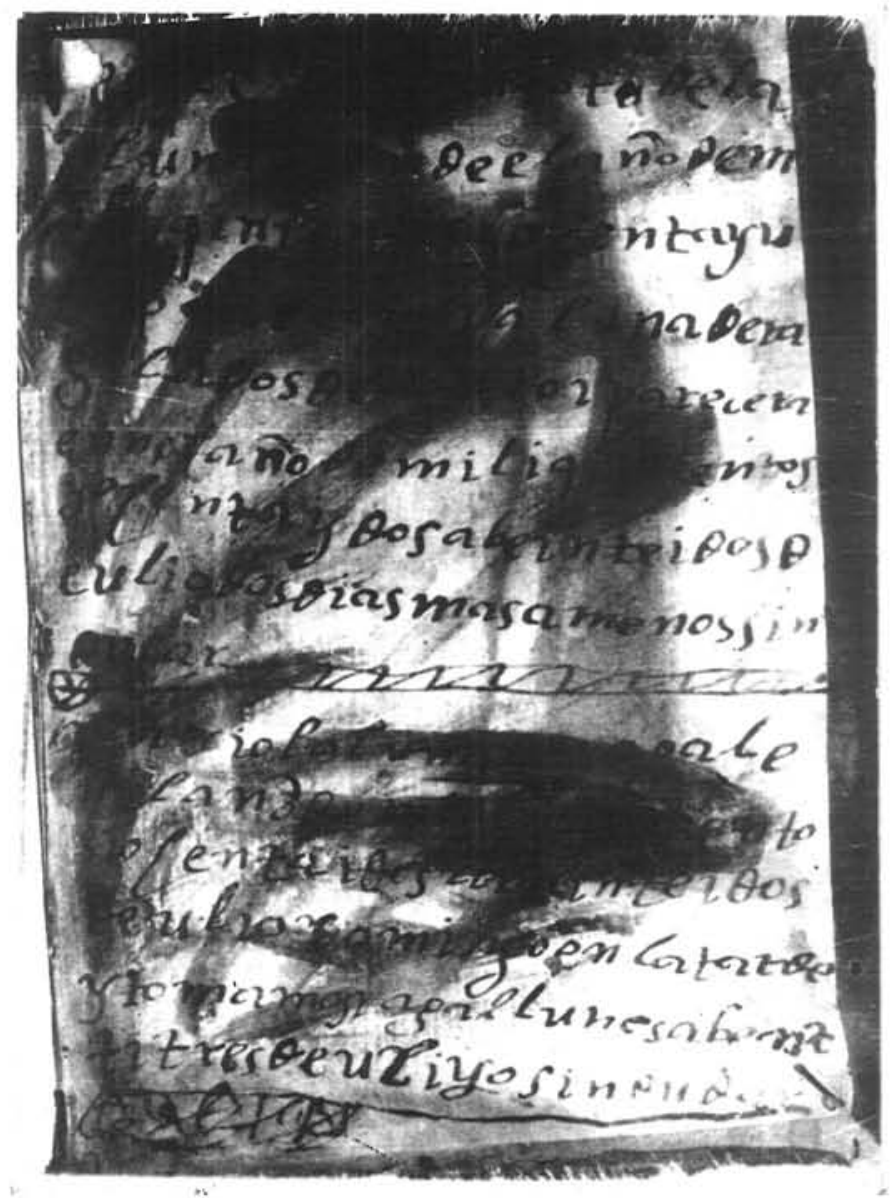

Guarda inicial, folio 1. 


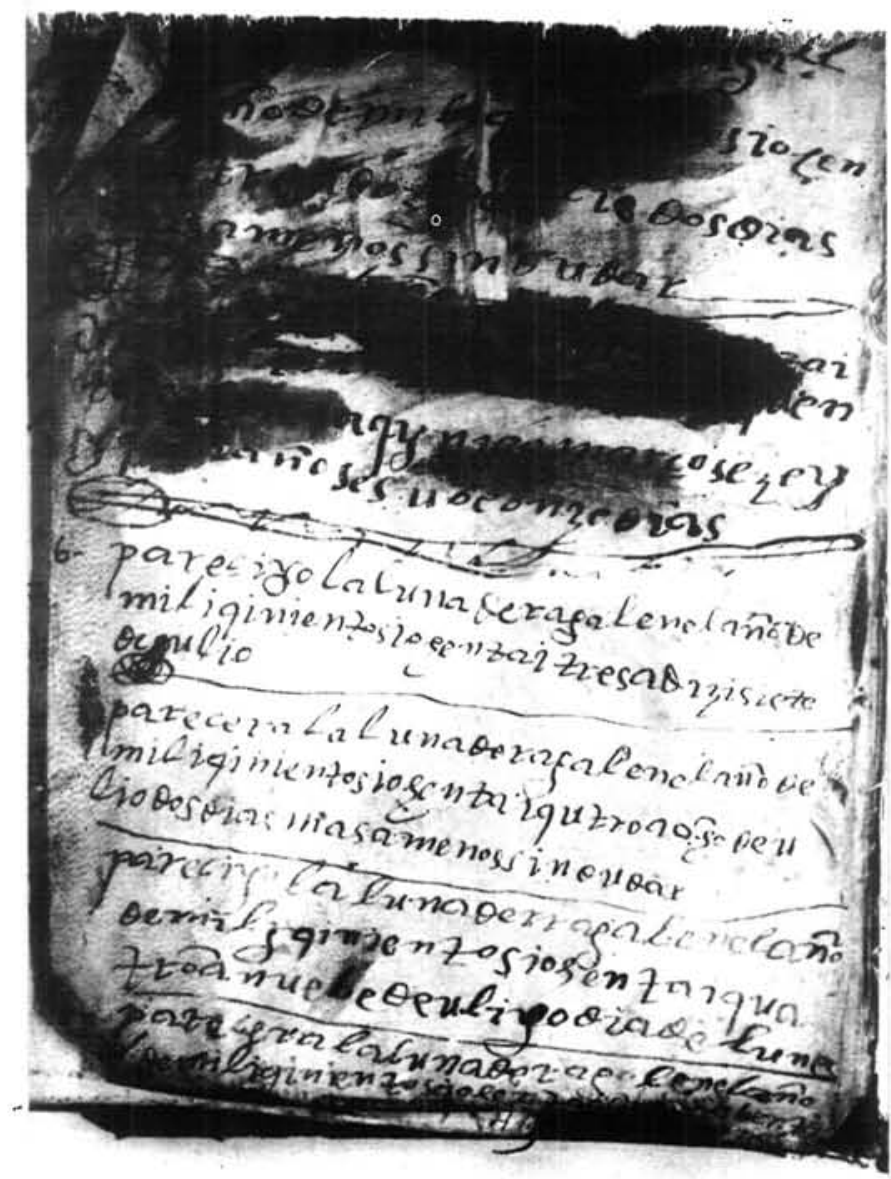

Guarda inicial, folio 2. 


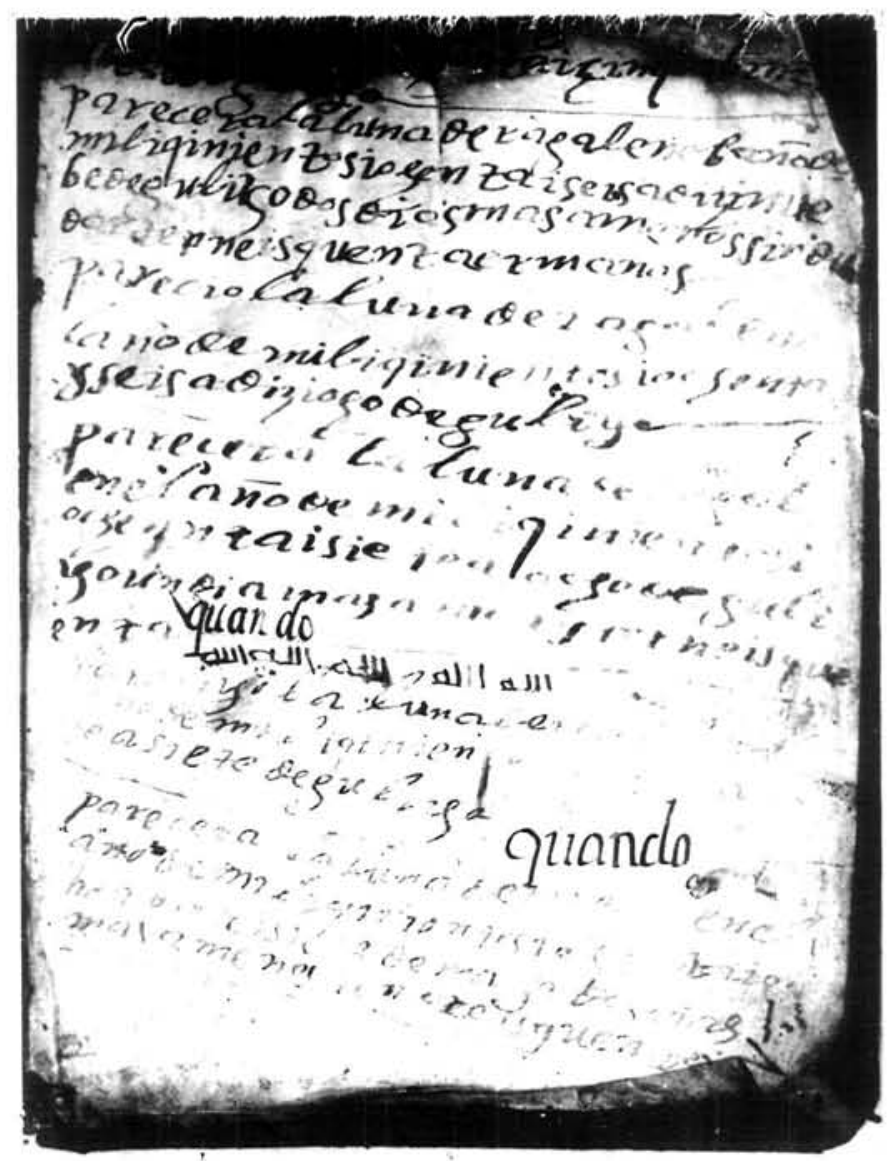

Guarda inicial, folio 3. 
10 En el año de mil i qinientos / i setenta i nuebe murió mi algüelo, el Juebes Santo (Santo) sin can/Panas lo-nterramos (42). Miguel escriba/no, perdónelo el Senior (43). Emin/.

15 Yo Luis escribano menor me calsé en el año de mil i cinientos / i setenta i dos con Jirónima la / Nabarra (44), por Sa[n] Migel del Bende/mas/l.

fol. 2 En el año de mil i qinientos / y ochênta (sic) i dos murió mi erm[a]/no Muca, biernes a nueve de m/arco, perdónolo el Señor emint.

5 En el año de mil i qinientos / y setenta i ojo (45) nació mi ijo / e[n] la noje (46) de los reies para bien / sea amen/.

10 En el año de mil i qinientos / y setenta i cinco nació mi ija / yera el día de arafa i naciyó / a(n) benticinco de mar[co] para bien / sea amen. I en nel año (47) antes (48)/ murfió] mi ermano Lope qe lo tomó / el terral (49), perdónelo el Señorl.

15 En el año de mi i qinientos / y ochênta (50) (sic) muirió mi padre en el / mes de nobienbre, perdónelol el Señor (51) emin. Yera aromadan (?) (52)/l.

fol. 3 En Navidal / pariyó si fue / dereja (53) la que[n]tta de ello, / y al prencilpiy[o] de janeroll.

\section{Método y cálculo de las lunas de rajab}

El morisco explica en el folio 2 de las guardas iniciales el sistema que se ha de seguir para calcular la lunación del mes de rajăab, durante los quince o dieciséis años siguientes, tal como parece indicar al decir:

se prencipia el quento de Africa a [ = para] qynze

y marco seze

(42) En el ms. lo-nteramos.

(43) La lectura es dudosa. Son posibles las lecturas senror y senior.

(44) En el ms. nabara.

(45) En el ms. ohô.

(46) En el ms. nohè.

(47) En el ms. anño.

(48) La lectura es difícil.

(49) En el ms. teral.

(50) Sin duda la lectura correcta sea ochênta, pues la $c$ está debajo de la $h$.

(51) En el ms. Senor.

(52) La lectura es muy dificil. Posiblemente se trata del mes de Ramadán.

(53) En el ms. dere $\mathcal{Q} a$. 


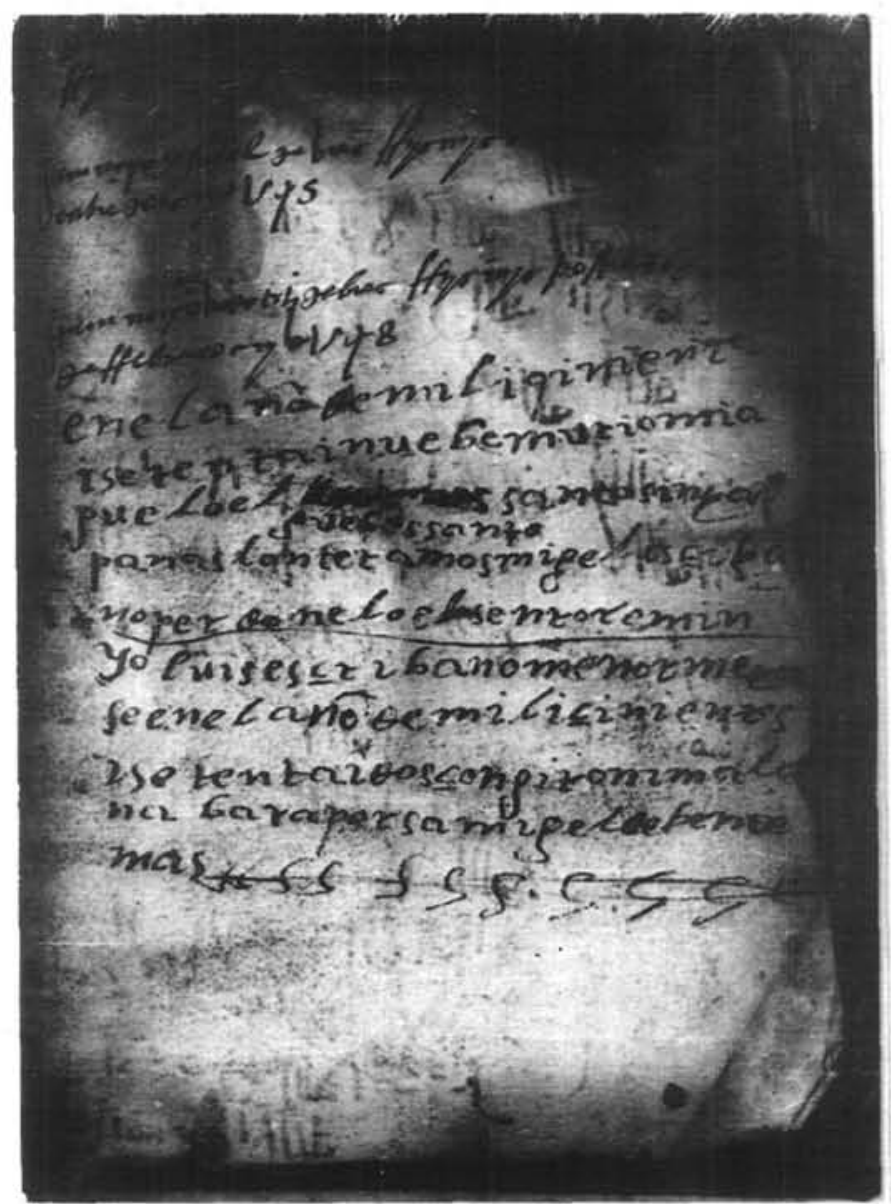

Guarda final, folio 1. 


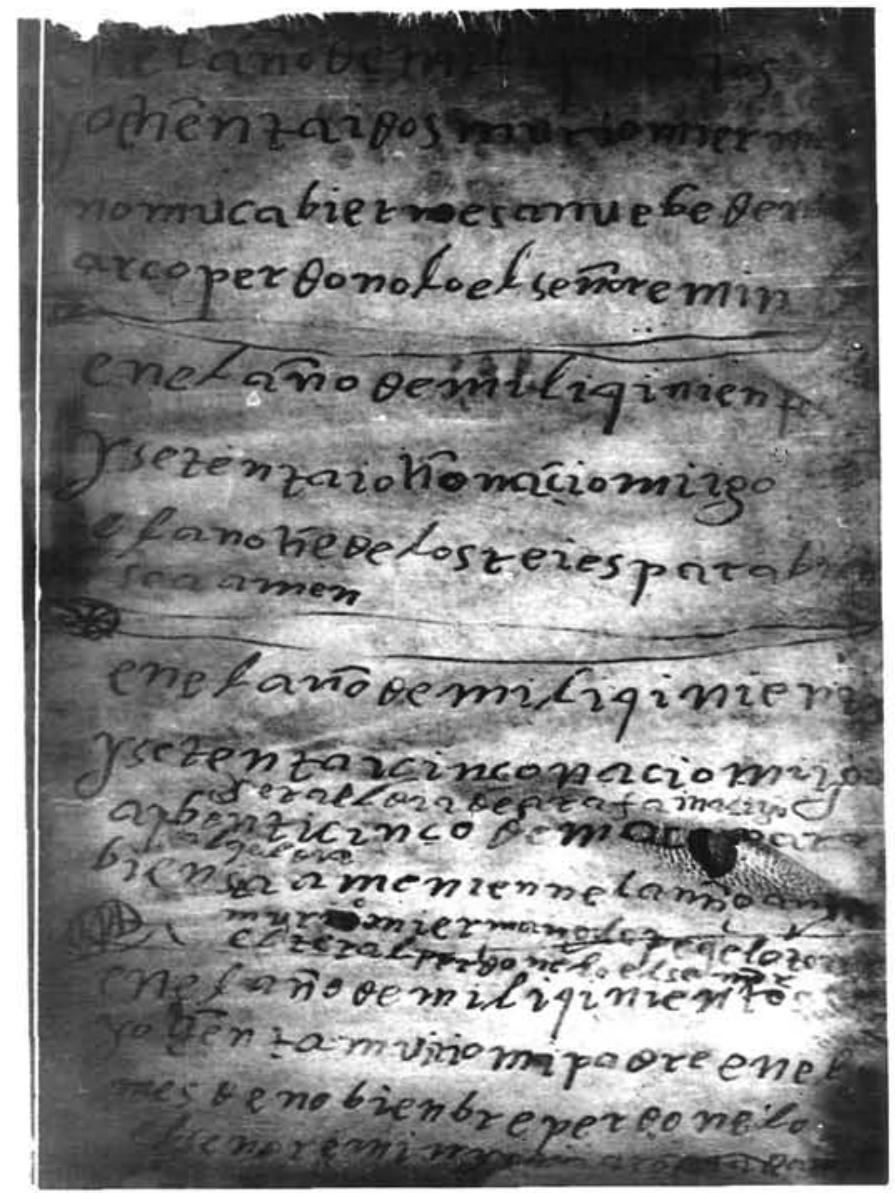

Guarda final, folio 2. 


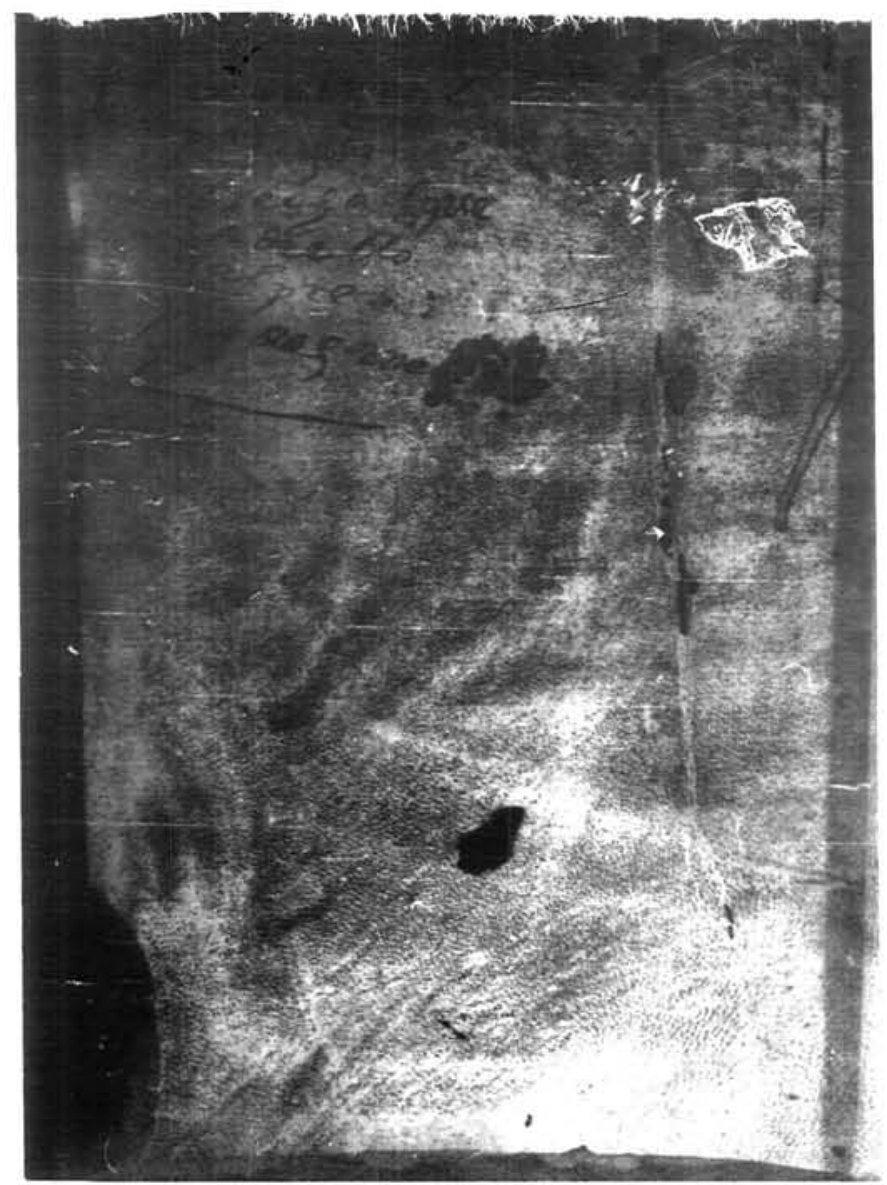

Guarda final, folio 3. 
según se incluyan o no en dicho cálculo las lunaciones correspondientes al mes de marzo (54). Esto es, si se incluyen las tres lunaciones correspondientes al mes de marzo (años 1594, 1595 y 1596), el cálculo sería para dieciséis años, si en cambio sólo se incluyen dos el cálculo es, evidentemente, para quince.

Una expresión idéntica se encuentra en el ms. J. 4 en el que se dice:

prencipia el quento de Africa de la luna,

a catorze i marco qynze.

esto es según se excluya o no lunación de marzo de 1594, ya que en este ms. el cómputo se inicia en 1580, mientras que el J. XIII se hace a partir de 1581.

El método consiste en restar once días (55) a la fecha del calendario cristiano en la cual ha tenido lugar la última aparición real de la luna de rajab. Procedimiento que se repetirá en los años sucesivos:

y qada año se sube onze dias.

De acuerdo con este sistema el amanunse nos ofrece las apariciones reales y las hipotéticas, es decir, las obtenidas por medio del sistema de cálculo indicado, desde 1581 hasta 1588, restando once días a la fecha de la última aparición real, esto es a la del 2 de agosto de 1581, obteniendo así la data hipotética del próximo año, 22 de julio de 1582. La comprobación de ésta tendrá lugar precisamente cuando se perciba visualmente el inicio del cuarto creciente del mes objeto de cálculo (36). En ese momento podrá hacer el cálculo de la entrada de la luna del año siguiente, y cuando ésta tenga lugar la del siguiente, y así sucesivamente. Para una mejor comprensión de lo dicho doy a continuación en extracto las fechas que anota el morisco:

Aparición real
$[13$ de agosto de 1580$]$ (57)
2 de agosto de 1581
22 de julio de 1582
17 de julio de 1583
9 de julio de 1584
29 de junio de 1585
18 de junio de 1586
7 de junio de 1587

\section{Aparición teórica}

22 de julio de 1582

12 de julio de 1583

8 de julio de 1584

29 de junio de 1585 (58)

19 de junio de 1586

8 de junio de 1587

27 de mayo de 1588

(54) Hipotéticamente las lunaciones de răăb que tuvieron lugar en marzo, según este cálculo, serian tres: la del 23 del año 1594 , la del 12 de 1595 y la del dia 1 de 1596

(55) En el ms. J. 4 se dice al explicar el método: i qada año se sube onze días, pero al iniciar el cálculo dice: i se sube a qada año diez días. El cálculo astronómico se realiza, sin duda, a partir de la primera cifra.

(56) Si las condiciones atmosféricas impiden su percepción visual «se da un día de plụs a la lunación que se computa - [...]-, y cumplida ésta, se inicia la cuenta de la siguiente luna, aunque su entrada no se haya testificado por cualquier circunstancia, pues se presupone que, obligatoriamente, ha de haberse producido yam, cfr. OCAÑA JIMÉNEZ, M.: Tablas de conversión de datas islámicas a cristianas y viceversa, CSIC, Madrid-Granada, 1946, págs. 10-11.

(57) Esta es la data que aparecen en el ms. J. 4. Véase nota 8.

(58) La aparición de la luna de rajab de los años 1585, 1586 y 1587 tiene lugar en el mes de junio, no en el de julio como dice el morisco, sin duda, por error. Por ello corrijo el mes. 
En la anotación de fechas realizada por el morisco se constantan dos irregularidades: una, las datas de la lunación de 1583, consecuencia, sin duda, de la reforma del calendario cristiano que tuvo lugar en 1582, y que motivó la supresión de los días 5 al 14 de octubre, ambos incluidos; y dos, la de junio de 1585, en la que la aparición teórica y real coinciden, habiéndose restado diez días (59). El morisco sabe que la cuenta astronómica que hace es totalmente teórica, y que puede oscilar la fecha por él propuesta en uno o dos días, de ahí que a cada cálculo le siga una apostilla en la que se prevé el error:

un día más o menos sin dudar.

o incluso:

dos días más o menos sin dudar.

Igualmente sabe que los meses islámicos no tienen una duración fija y constante (60), lo que ha motivado la introducción de numerosas correcciones en la cuenta musulmana, en la cual ya se «prevé las entradas de los meses lunares con un margen de \pm 1 día de error» (61).

La correspondencia de las fechas del calendario cristiano que da el morisco para el mes de rajab, con las del calendario musulmán son, según las tablas de conversión ofrecidas por Ocaña Jiménez, las siguientes (entre paréntesis doy la fecha del calendario cristiano):

2 de rajab del año $987 \mathrm{~h}$

$(=13$ de agosto de 1580$)$

2 de raǰab del año $988 \mathrm{~h}$

$(=2$ de agosto de 1581)

1 de rajab del año $989 \mathrm{~h}$

(= 22 de julio de 1582)

21 de jumāda II del año 990h

(= 17 de julio de 1583)

1 de rajab del año $991 \mathrm{~h}$

( $=9$ de julio de 1584)

1 de rajab del año 992-3h

$(=29$ de junio de 1585)

1 de rajab del año $994 \mathrm{~h}$

( = 18 de junio de 1586)

1 de rajab del año 995h

$(=7$ de junio de 1587)

1 de rajab del año 989h

(= 22 de julio de 1582)

26 de jumäda ll del año $990 \mathrm{~h}$

(= 12 de julio de 1583)

29 de jamāda del año 991h

(= 8 de julio de 1584)

1 de rayab del año 992-3h

(= 29 de junio de 1585)

2 de raǰab del año $994 \mathrm{~h}$

(= 19 de junio de 1586)

2 de rajab del año 995h

(= 18 de junio de 1587)

1 de rajab del año 996h

(= 27 de mayo de 1588)

\section{Luis Escribano Menor}

Los estudios sobre copistas y escribanos están aún en su fase inicial. Consuelo López-Morillas presentó en un trabajo titulado «Copistas y escribanos moriscos» (62)

(59) Recuérdese lo dicho en la nota 35. No obstante, se puede afirmar, por la información que el texto nos ofrece, que si se restan once días la aparición teórica y real coinciden, mientras que si son diez los dias restados, la aparición real tiene lugar un dia antes.

(60) Cfr. OCAÑA JIMÉNEZ, M. op. cit., pág. 19

(61) Cfr. OCAÑA JIMÉNEZ, M.: op. cit, pág. 11.

(62) LÓPEZ-MORILLAS, C.: "Copistas y escribanos moriscos", en Actes du // Symposium International du C.I.E.M. 
el primer intento serio para un estudio sobre la escribanía morisca. En dicho trabajo planteó las dificultades más importantes que surgen en torno a este tema (63), y dio noticia de una serie de amanuenses (64). Por ello me limitaré a completar y aclarar los datos que tenemos sobre la figura de Luis Escribano Menor, que ya trató la profesora López-Morillas (65).

En las guardas que estamos estudiando aparecen varios datos referidos a Luis Escribano. A saber:

- Era nieto de Miguel Escribano, el cual murió en 1579.

- Su padre murió en 1580.

- Dos de sus hermanos Lope y Muça murieron en 1574 y 1582, respectivamente.

- Se casó en 1572 con Jerónima la Navarra, con la que tuvo al menos dos hijos en 1575 y en 1578 .

Datos biográficos que completan los hasta ahora conocidos, y que encontramos en varios manuscritos, los cuales ya se han puesto de manifiesto en varias ocasiones y que voy a recordar.

En un ms. del siglo XVI se dice:

En el año de mil y quinientox y çincuenta y uno naçi yo Luis Escribano fiyo de Luis Escribano y de María la Monja en lox çaguerox díax del mex de xetiembre y fue bautizado a xeix díax del mex de octubre para lo que querrá Allah mi señor y fue mi padrina Cándida de Aboçaque y mi padrino el maextro (66).

En la carpeta número XCVIII de la Junta, en el bloque de folios cuarto, hay varios fragmentos de escritura castellana. Uno de ellos es un recibo del pago efectuado el 21 de septiembre de 1593, en Almonacid, por Melchor Mediana, «jurado de Almonezir de la Sierra», a Luis Escribano (67).

Posibleménte estemos en todos los casos ante la misma persona, esto es ante Luis Escribano «Menor». Nos llama la atención la denominación de «menor», que tan sólo aparece en las guardas que estamos tratando:

yo Luis Escribano menor me casé en el año de mil i cinientos i setenta i dos...

López-Morillas ya apuntó, no sin reservas, que la designación «mayor» o «menor», que solía aparecer junto a ciertos nombres, hacia referencia a la edad y que se podía explicar por la existencia en el mismo lugar de otro amanuense con el mismo nombre (68). Efectivamente, Luis Escribano sólo añade a su nombre el adjetivo «me-

sur: Religion, Identité et Sources Documentaires sur les Morisques Andalous, Túnez, 1984, t. Il, págs. 71-78. Véase también de esta misma autora «Más sobre los escribanos moriscos», en Les acters de la première table ronde du C.I.E.M. sur: La littérature aljamiado-morique: hybridisme lingüistique et univers discursif, Túnez, 1986, págs. 105-107.

(63) Cfr. LÓPEZ-MORILLAS, C., op. cit., págs. 71-72, 75 y 77.

(64) Cfr. LÓPEZ-MORILLAS, C., op. cit., págs. 75 y ss.

(65) Cfr. LÓPEZ-MORILLAS, C., op. cit., págs. 77-78.

(66) Ms. A, fol. 391 de los Padres Escolapios de Zaragoza. Cfr. RIBERA Y ASIN: Manuscritos árabes y aljamiados de la Biblioteca de la Junta, Madrid, 1912, pág. 262, nota 2. Cfr. LÓPEZ-MORILLAS, C., op. cit, pág. 77.

(67) Cfr. RIBERA Y ASÍN, op. cit,, pág. 254.

(68) Véase LÓPEZ-MORILLAS, C., op. cit., págs. 76-77. 
nor" en 1572, cuando su padre, Luis Escribano, aún vive o ejerce de escriba, estableciéndose así la diferenciación. Sin embargo cuando nos informa de su nacimiento y bautizo o cuando se hace el recibo de pago, ya no es necesario dicha indicación, precisamente porque en 1580 su padre ya había muerto.

\section{Léxico}

Recojo una serie de voces que fonética, morfológica o semánticamente difieren de la norma castellana:

AGÜELO: «abuelo». Sin duda un vulgarismo.

ARAFA: «día de arafat: noveno día de la luna de $D \bar{u}$ hij.jat, en el cual los peregrinos visitan el monte de Arafat». Árabe عرفة 'arafat.

BENTE I DOS: «veintidós». Forma aragonesa. Alvar documenta en el siglo XIV la variante veint, y la explica por disimulación de la $i$ inicial respecto de la vocal tónica, i: viginti > viyinte > veint(e) (69).

BENTRITRES: «veintitrés». Vid. bente i dos.

BINTE I SIETE: «veintisiete». Voz aragonesa. Ya en el siglo XIII se documenta la variante vint(e) (70).

BINTINU[E]BE: «Veintinueve». Voz aragonesa. Vid. binte i siete.

DENDE: «desde». Preposición aragonesa.

DIZINUEBE: «diecinueve». Voz aragonesa. Alvar cita formas similares como dizesiete, dezisiet, diciséis, diziocho. Es el resultado analógico (71).

DIZIOJO: «dieciocho». Vid. dizinuebe.

DIZISIETE: «diecinueve». Vid. dizinuebe.

E: «es». Presente de indicativo, $3 .^{\text {a }}$ persona singular, del verbo ser. Forma aragonesa.

EMIN: «amén». Voz árabe: ¿یl emin.

EN NEL: «en el».

IJO, -A: «hijo, -a». Obsérvese la ausencia de $f$-inicial propia de la pronunciación castellana de finales del siglo XVI.

JANERO: «enero». Voz aragonesa.

JIRONIMA: «Gerónima».

JULIYO: «julio». Esta vez es sin duda una transliteración gráfica de esta misma palabra pero escrita en caracteres árabes بy yuliyo. Las variantes ulio, uliyo son ultracorrecciones surgidas al transcribir estas palabras en caracteres latinos. El diptơngo iyo: juliyo, uliyo, y también en naciyó, pareciyó, son igualmente reflejo de un texto previo en el que se grafía dicho diptongo según las normas ortográficas que hemos podido constatar en los textos aljamiado-moriscos escritos en caracteres árabes (72).

LO-NTERRAMOS: «lo enterramos».

MUIRIO: «murió». Forma analógica.

NACIYO: «nació». Véase lo dicho para juliyo.

(69) Cfr. ALVAR, M.: El dialecto aragonés, Madrid, 1953, pág. 210.

(70) Cfr. ALVAR, M.: ibidem.

(71) Cfr. ALVAR, M.: ibidem.

(72) En mi tesis doctoral dedico un capítulo a tratar el probiema de la representación de diptongos e hiatos. 
NAVIDAL: «navidad». Voz aragonesa.

PARECIYO, PARECYO: «pareció». Véase lo dicho para juliyo.

QUENTO: «cálculo, cómputo».

QYNZE: «quinze».

RAĞAL: «éptimo mes del calendario musulmán». Árabe - rajab. Variantes rağel, con pronunciación romance para la a árabe, rrağal, rağall.

RAĞEL: Vid. rağal.

SENIOR: «señor». Voz aragonesa.

SEZE: «dieciséis». Resultado aragonés etimológico procedente de sedecim.

TERNEIS: «tendréis». Futuro con metátesis frecuente en aragonés.

TERRAL: «en catalán vent terral o simplemente terral es un tipo de viento que viene de la tierra» (73). También «masa de tierra, acumulación de tierra».

[TOMAR]1: "comenzar»: y tomamos rağal lunes a bentitrés. Esta acepción posiblemente deba explicarse de un calco del verbo árabe iخl ahada que significa «tomar, comenzar».

[TOMAR]2: «Coger». Este valor está recogido el DCELC.

ULIO: «julio». Posiblemente sea una ultracorrección. Vid. juliyo.

ULIYO: «julio». Posiblemente se trate de una ultracorrección. Vid. juliyo.

YERA: «era». Imperfecto de indicativo. En este tiempo es normal la diptongación de é, breve y tónica, en el dialecto aragonés. Aparece en el Poema de Yúçuf y pervive aún en la lengua viva (74).

\section{Addenda}

Estando este trabajo en la redacción de SHARQ AL-ANDALUS para su publicación, tuve conocimiento del artículo de Alberto Montaner Frutos «El depósito de Almonacid y la producción de la literatura aljamiada (En torno al ms. Misceláneo XIII)», $A F A, \mathrm{XLI}$, págs. 119-152, en el que se editaban las guardas que han sido el objeto de mi trabajo, y que evidentemente no pude consultar. Sin embargo, la utilización del trabajo de Montaner es obligada para conocer diferentes aspectos que no fueron tratados en mi estudio, puesto que ello, sin duda, redundará en una mejor comprensión de este interesantísimo s. XIII.

(73) Cr. POMPEU FABRA: Diccionari General de la Llengua Catalana, s.v. TERRAL.

(74) Cir. ALVAR, M., op. cit., pág. 232. 